\title{
Bone Age
}

National Cancer Institute

\section{Source}

National Cancer Institute. Bone Age. NCI Thesaurus. Code C156787.

An indication of skeletal growth potential based on skeletal maturity indicators, such as radiologic imaging of growth plates. 